\title{
Multicomponent Metal Oxide Nanostructures: Fabrication and Study of Core Issues to Improve Gas Sensing Performance ${ }^{+}$
}

\author{
Vardan Galstyan 1,*, Andrea Ponzoni 2, Iskandar Kholmanov ${ }^{3}$, Marta M. Natile 4, \\ Antonella Glisenti ${ }^{4}$, Giorgio Sberveglieri ${ }^{1}$ and Elisabetta Comini ${ }^{1}$ \\ 1 Sensor Lab, Department of Information Engineering, University of Brescia, Via Valotti 9, 25133 Brescia, \\ Italy; giorgio.sberveglieri@unibs.it (G.S.); elisabetta.comini@unibs.it (E.C.) \\ 2 National Research Council, National Institute of Optics (INO) - Unit of Brescia, Via Branze 45, \\ 25123 Brescia, Italy; andrea.ponzoni@ino.it \\ 3 Department of Mechanical Engineering, The University of Texas at Austin, Austin, TX 78712, USA; \\ iskandar.kholmanov@austin.utexas.edu \\ 4 National Research Council (CNR), Institute of Condensed Matter Chemistry and Technologies for Energy \\ (ICMATE), Department of Chemical Sciences, University of Padova, Via F. Marzolo 1, 35131 Padova, Italy; \\ martamaria.natile@unipd.it (M.M.N.); antonella.glisenti@unipd.it (A.G.) \\ * Correspondence: vardan.galstyan@unibs.it; Tel.: +39-0303-715-702 \\ † Presented at the Eurosensors 2018 Conference, Graz, Austria, 9-12 September 2018.
}

Published: 30 November 2018

\begin{abstract}
We have obtained and studied the sensing properties of porous titania-based nanostructures. The materials have been prepared using cost-effective techniques. The morphological and structural analyses of the prepared materials have been performed. The sensing properties of the samples have been studied towards carbon monoxide. The obtained results demonstrate that the prepared structures are promising for the potential applications in the area of chemical sensors for the environmental monitoring.
\end{abstract}

Keywords: metal oxide; nanostructures; chemical gas sensor

\section{Introduction}

Atmospheric pollution due to the combustion of fossil fuels and excessive use of insecticides and pesticides in agriculture is considered as a major problem of environmental health. Gases like CO, $\mathrm{SO}_{x}, \mathrm{NO}_{x}, \mathrm{H}_{2} \mathrm{~S}$ and acetone are continuously released into the environment and posing serious impacts to the human health [1,2]. Among these gases the carbon monoxide (CO) is a toxic, hazardous and odorless gas. CO promptly combines with the hemoglobin, forms carboxyhemoglobin and restrict the transportation of $\mathrm{O}_{2}$ to the tissues. The aforementioned processes can cause headache, dizziness, nausea, coma and death in presence of the $\mathrm{CO}$ certain concentrations [3]. CO can release into the atmosphere due to the incomplete combustion of the fossil fuels during industrial processes and in the automobiles. In order to reduce the hazardous effects of $\mathrm{CO}$ gas, its fast and highly reliable monitoring is required. Good chemical and catalytic properties of transition metal oxide materials make them potential candidates for the fabrication of gas sensing devices [4,5]. In particular, metal oxide nanostructures with the large surface area and the surface defect density play important roles in the adsorption of different gaseous species [6].

Herein, we successfully synthesized $\mathrm{Nb}$-contained titania tubular structures and studied their gas sensing properties. The materials were prepared by combination of magnetron sputtering and electrochemical anodization methods. The morphological and structural analysis of samples were 
carried out. The gas sensing properties of materials were tested towards $\mathrm{CO}$. Investigations have shown that we developed a cost-effective synthesis method for the fabrication of small-size gas sensor devices for $\mathrm{CO}$ detection.

\section{Materials and Methods}

Tubular arrays were prepared by the electrochemical anodization of metallic $\mathrm{Nb}-\mathrm{Ti}$ thin films deposited on alumina substrates. The metallic films were deposited by means of radio frequency (RF) magnetron sputtering. Then, the deposited films were anodized using a two-electrode configuration (Figure 1). Anodization process was perforemd at room temperature. As-prepared samples were treated at $400{ }^{\circ} \mathrm{C}$. The morphological and the structural analyses of the prepared materials were carried out. The platinum electrodes were deposited on the surface of structures using RF magnetron sputtering for gas sensing characterization. The platinum heater was deposited on the backside of the substrates. The sensing properties of structures were studied toward CO. Gas sensing measurements were carried out by means of the flow-through technique at atmospheric pressure. A constant synthetic airflow was used as carrier gas for the analyte dispersion. The gas mixture for the sensing measurements was obtained by means of a computer controlled gas flow system. During the measurements the relative humidity in the test chamber was 30\%. The conductance of the obtained sensors was monitored by means of the volt-amperometric technique at constant voltage.

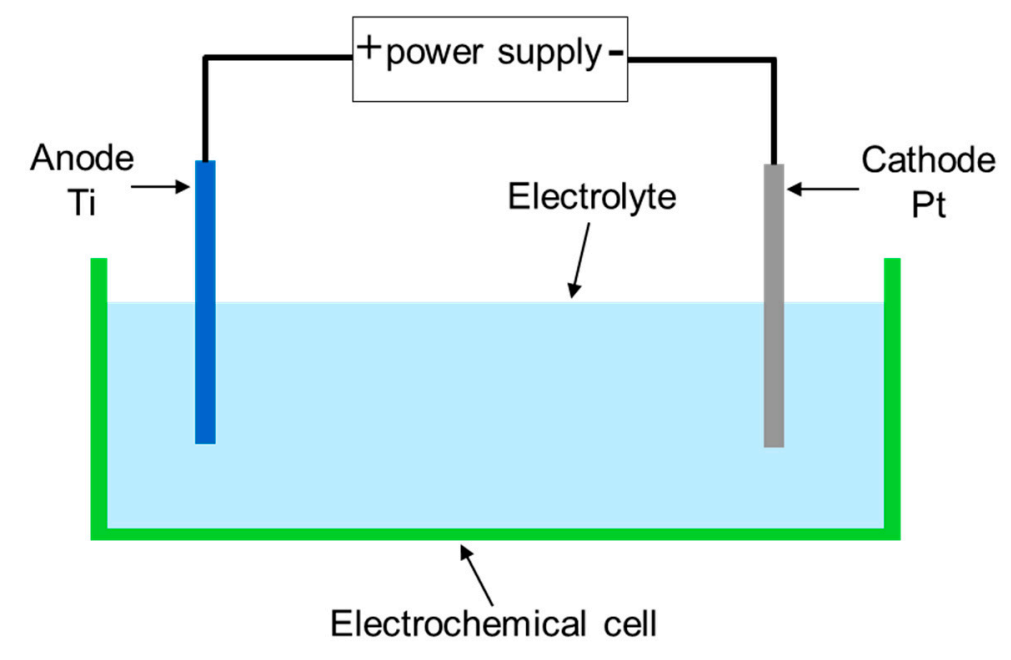

Figure 1. The scheme of the electrochemical cell for the anodization of metallic films.

\section{Results and Discussion}

The morphological analysis of tubular arrays were performed by means of scanning electron microscopy (SEM) using a LEO 1525 microscope equipped with field emission gun. Figure 2 reports the SEM image of tubular arrays. The inner diameter and the length of nanotubes are about 30 and $900 \mathrm{~nm}$, respectively. Figure 3 reports the dynamic response of the structures towards CO. The conductance of the material increases upon interaction with the $\mathrm{CO}$, which is a typical behavior for the $n$-type semiconductor material. The sensing mechanism of the $n$-type semiconductor depends on the adsorption/desorption reactions of gas molecules on the surface of material, that leads to the changes in its electrical conductance. The $\mathrm{CO}$ are oxidized to $\mathrm{CO}_{2}$ due to the interaction with oxygenated species adsorbed on the surface of material. This oxidation process releases the electrons back to the conduction band of the structure. The interaction mechanism of the obtained structure with $\mathrm{CO}$ is described in terms of reduction of the material surface through interaction with surface oxygen species according to Equation (1):

$$
\mathrm{CO}_{g}+\mathrm{O}_{a d s}^{-}=\mathrm{CO}_{2, g}+e^{-}
$$


The dynamic response curve also demonstrates the reversible gas sensing properties of the prepared structure towards $\mathrm{CO}$ gas. The response of the material was proportional to the $\mathrm{CO}$ gas concentration. The obtained results are promising for the application of the prepared structure in chemical sensing devices.

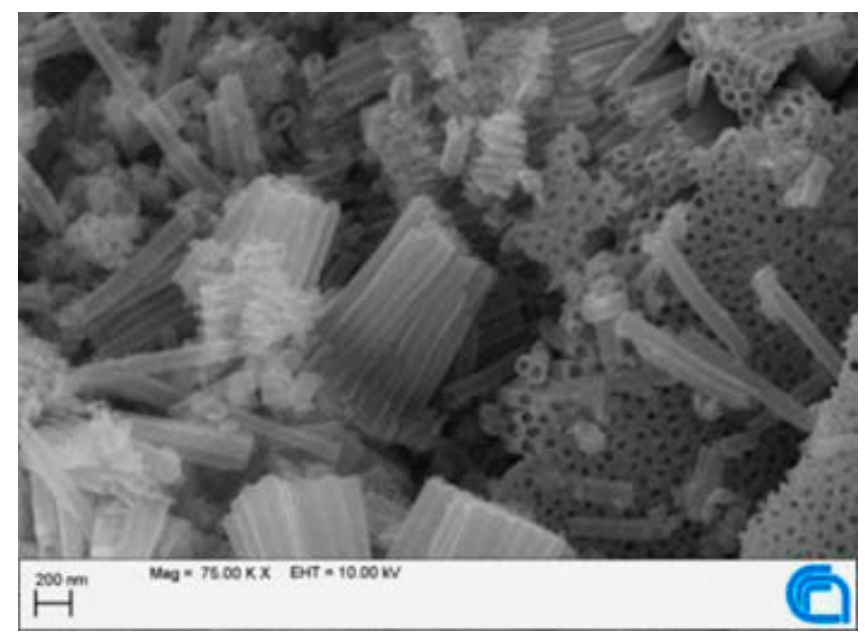

Figure 2. SEM image of the obtained nanotubes.

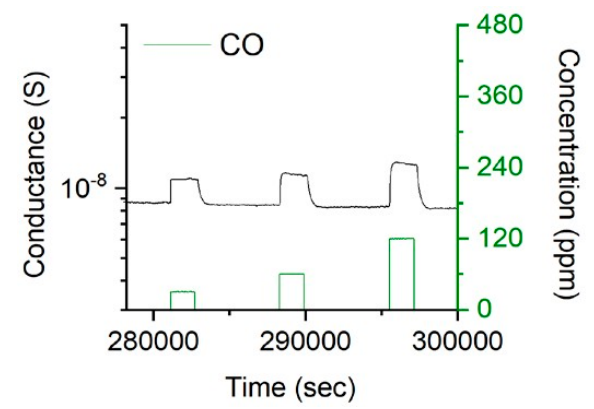

Figure 3. Variation of the structure conductance as a function of the introduction of different concentrations of $\mathrm{CO}(30,60$ and $120 \mathrm{ppm})$ at $300{ }^{\circ} \mathrm{C}$.

Author Contributions: The authors contributed equally to this work.

Conflicts of Interest: The authors declare no conflict of interest.

\section{Conclusions}

We have prepared $\mathrm{Nb}$-contained titania tubular structures by the electrochemical anodization technique for the development of gas sensing systems. The morphological analysis of samples have shown that well-aligned and highly ordered tubular arrays have been obtained on alumina substrates. The gas sensing properties of the obtained structures have been investigated towards $\mathrm{CO}$ gas. The prepared materials have shown good gas sensing performance towards $\mathrm{CO}$ at the relatively low operating temperature. The obtained results show that the prepared tubular structures are promising for the development of gas sensing devices to perform environmental monitoring.

\section{References}

1. Sanidas, E.; Papadopoulos, D.P; Grassos, H.; Velliou, M.; Tsioufis, K.; Barbetseas, J., Papademetriou, V. Air pollution and arterial hypertension. A new risk factor is in the air. J. Am. Soc. Hypertens. 2017, 11, 709-715, doi:10.1016/j.jash.2017.09.008.

2. McCullough, S.D.; Dhingra, R.; Fortin, M.C., Diaz-Sanchez, D. Air pollution and the epigenome: a model relationship for the exploration of toxicoepigenetics. Curr. Opin. Toxicol. 2017, 6, 18-25, doi:10.1016/j.cotox.2017.07.001. 
3. Gullotta, F.; di Masi, A.; Coletta, M.; Ascenzi, P. CO metabolism, sensing, and signaling. BioFactors 2012, 38, 1-13, doi:10.1002/biof.192.

4. Malwadkar, S.S; Gholap, R.S.; Awate, S.V.; Korake, P.V.; Chaskar, M.G.; Gupta, N.M. Physico-chemical, photo-catalytic and $\mathrm{O}_{2}$-adsorption properties of $\mathrm{TiO}_{2}$ nanotubes coated with gold nanoparticles. Photochem. Photobiol. A. 2009, 203, 24-31, doi:10.1016/j.jphotochem.2008.12.013.

5. Galstyan, V.; Comini, E.; Ponzoni, A.; Sberveglieri, V.; Sberveglieri G. ZnO quasi-1D nanostructures: Synthesis, modeling, and properties for applications in conductometric chemical sensors. Chemosensors 2016, 4, 6, doi:10.3390/chemosensors4020006.

6. Galstyan, V.; Comini, E.; Faglia, G.; Sberveglieri, G. $\mathrm{TiO}_{2}$ Nanotubes: Recent advances in synthesis and gas sensing properties. Sensors 2013, 13, 14813-14838, doi:10.3390/s131114813.

(C) 2018 by the authors. Licensee MDPI, Basel, Switzerland. This article is an open access article distributed under the terms and conditions of the Creative Commons Attribution (CC BY) license (http://creativecommons.org/licenses/by/4.0/). 